\title{
NECESIDAD Y LO QUE DEPENDE DE NOSOTROS. SOBRE LA INTERPRETACIÓN DE MARCELO BOERI DEL COMPATIBILISMO ESTOICO
}

RiCARDO SALLES

Instituto de Investigaciones Filosóficas Universidad Nacional Autónoma de México rsalles@servidor.unam.mx

RESUMEN: Este trabajo discute la interpretación de Marcelo Boeri sobre el compatibilismo estoico; esto es, la tesis de que es compatible con el determinismo que rige al mundo natural el que podamos ser genuinamente responsables de nuestras acciones. Según Boeri, los estoicos intentaron conciliar las dos cosas abriendo un margen de indeterminación gracias al cual nuestras acciones no están sujetas a la necesidad que domina los demás fenómenos naturales. La discusión que se ofrece aquí se basa en un análisis del concepto antiguo de lo que depende de nosotros y de los conceptos estoicos de determinismo y modalidad.

PALABRAS CLAVE: necesidad, responsabilidad, compatibilismo, estoicos

SUmmary: This paper discusses Marcelo Boeri's interpretation of Stoic compatibilism, the thesis that natural determinism does not rule out that we can genuinely be responsible for our actions. According to Boeri, the Stoic hold that this is so because our actions are to a great extent free from determination. The discussion of this interpretation is based on an analysis of the ancient concept of what depends on us and of Stoic concepts of determinism and modality.

KEY WORDS: necessity, responsibility, compatibilism, Stoics

En una serie de tres artículos publicados en años recientes, ${ }^{1}$ Marcelo Boeri ha desarrollado una interpretación original sobre la naturaleza del compatibilismo estoico, la cual, por su complejidad y alto nivel de argumentación, merece una discusión detallada.

La tesis principal de Boeri es que los estoicos antiguos, a pesar de defender que el mundo natural en su conjunto está sujeto a un determinismo estricto, abrieron un margen de indeterminación para dar cabida a la atribución justificada de responsabilidad. En esto justamente consiste su compatibilismo: el determinismo es compatible con que merezcamos el elogio o la censura, porque el primero no abarca absolutamente todo y existe al menos un dominio que escapa a la necesidad que atañe a los fenómenos naturales, a saber, el de nuestras acciones y la psicología que subyace en ellas. En palabras del autor

\footnotetext{
${ }^{1}$ Boeri 1997a, 1997b y 2000.
} 
el estoicismo antiguo planteó la posibilidad de la responsabilidad en términos de "lo que depende de nosotros" y [...] la teoría que podemos reconstruir a partir de los fragmentos existentes muestra que su concepto de responsabilidad no se reduce a la capacidad de examinar críticamente las impresiones; algunos muestran que la no existencia de una causa necesaria que determine mi acción es un componente relevante para explicar la responsabilidad. (Boeri 2000, p. 14)

Por consiguiente, los estoicos habrían concedido al incompatibilista que hay, hasta cierto punto, una tensión irreductible entre determinismo y responsabilidad. Sin embargo, con el fin de no caer en la posición de un determinista duro que simplemente afirma que nunca merecemos el elogio y la censura, porque el determinismo lo abarca absolutamente todo, según Boeri, los estoicos habrían argumentado, como señalé antes, que, a fin de cuentas, no todo está sujeto a un determinismo estricto.

Esta forma de interpretar la posición estoica no es nueva. Para tomar un ejemplo, en Necesidad, causa y culpa, Sorabji la defiende al sostener que los estoicos "se retractaron de la necesidad" para dar cabida a la moralidad. ${ }^{2}$ Más recientemente, en un libro importante sobre el determinismo estoico, Bobzien ha sostenido una tesis parecida al afirmar que, para Crisipo, nuestras acciones no son necesarias en un sentido importante y, por eso mismo, dependen de nosotros. ${ }^{3}$ Uno de los aspectos novedosos de la interpretación de Boeri es el modo en que sustenta este tipo de lectura. Hasta donde puedo ver, los argumentos que él aduce son de dos tipos. Por un lado, están los de tipo textual, que se apoyan en una reinterpretación de pasajes clave: (i) el que introduce la distinción entre la causa externa y la causa interna de nuestras acciones, en Cicerón, De Fato 39-44:4 (ii) el que se refiere a las características propias de cada cosa en la scala naturae de los estoicos, que aparece en el capítulo 13 del De Fato de Alejandro de Afrodisia, y el 35 del De Natura Hominis de Nemesio de Emesa; ${ }^{5}$ y (iii) el que emplea la noción de hechos codestinados, que figura en Cicerón, De Fato 28-29, y en Orígenes, Contra Celsum II 20. ${ }^{6}$ Por otro lado, están los argumentos de tipo conceptual, que descansan en consideraciones filosóficas generales acerca de las nociones de "lo que depende de nosotros" y de la de posibilidad de acciones alternativas.

${ }^{2}$ Sorabji 1980, cap. IV, en especial las pp. 113-114.

${ }^{3}$ Bobzien 1998, pp. 250-313.

${ }^{4}$ Boeri 1997b, pp. 164 y 164 n. 11, y 2000, pp. 32-38.

${ }^{5}$ Boeri 2000, pp. 38-39.

${ }^{6} \mathrm{He}$ defendido esta interpretación en Salles 2005. 
Debido al rigor filosófico con el cual Boeri desarrolla sus ideas y a su profundo conocimiento de las fuentes originales, sus argumentos representan un desafío agudo para quienes nos inclinamos a pensar que la postura estoica era más radical que la que él les atribuye. Según esta segunda interpretación, alternativa a la de Boeri, los estoicos habrían sostenido que (a) todas las acciones humanas y su psicología tienen una causa completamente suficiente y, por ende, no escapan al determinismo causal que rige a los demás fenómenos naturales, pero que (b) a pesar de esto, muchas de ellas merecen plenamente el elogio o la censura. ${ }^{7}$

Es importante advertir que las dos interpretaciones concuerdan en su forma de entender el determinismo estoico. Se trata de un determinismo causal que sostiene que todo suceso o estado de cosas tiene una causa, o conjunto de causas, completamente suficiente para que se dé ese suceso o estado de cosas. Por consiguiente, cada suceso o estado de cosas es necesario dada su causa. Además, el determinismo estoico es compatible con el cambio, pues cada una de las etapas de un cambio tiene ella misma una causa suficiente. Por ejemplo, se permite que en $t_{1} a$ sea $F$ y que deje de serlo en $t_{2}$, siempre y cuando $F a$ tenga una causa suficiente en $t_{1}$ y no $F a$ tenga una causa suficiente en $t_{2}$. Con ello, el determinismo estoico se aparta por ejemplo del determinismo más radical de los megarios que niega la posibilidad del cambio, y que Aristóteles describe y ataca en el capítulo 3 del libro 9 de la Metafísica. ${ }^{8}$ La divergencia entre las dos interpretaciones antes mencionadas se refiere, más bien, al dominio del determinismo y a la compatibilidad entre éste y la atribución justificada de responsabilidad a otras personas o a uno mismo. ¿Es posible la atribución justificada de responsabilidad si no existe un margen de indeterminación para nuestras acciones y su psicología, en el cual éstas carecerían de causa suficiente y, por lo tanto, ocuparían un dominio que el determinismo no abarca? Según Boeri, los estoicos sostuvieron que se necesitaba abrir ese margen y, con ello, afirmaron la incompatibilidad del determinismo con la responsabilidad y, a la vez, restringieron el dominio del determinismo de modo que excluyeron de él nuestras acciones y su psicología.

En lo que sigue no pretendo regresar a la interpretación por la cual yo mismo me inclino, opuesta a la de Boeri respecto de estos

${ }^{7} \mathrm{He}$ defendido esta interpretación en Salles 2005.

${ }^{8}$ El determinismo de los megarios se discute en Salles 2005, pp. xiv-xv. 
dos asuntos. ${ }^{9}$ Me limitaré a presentar y discutir la de Boeri, centrándome en sus argumentos conceptuales. En lo tocante a los argumentos de tipo textual, mi lectura de los pasajes difiere en algunos puntos importantes de la suya; pero prefiero dejar para otra oportunidad la discusión de estos argumentos, aunque me referiré a ellos brevemente al final de este trabajo.

\section{Los argumentos conceptuales}

Según lo apunté líneas atrás, Boeri sostiene que, para los estoicos, la responsabilidad es incompatible con el determinismo causal aplicado a nuestras acciones y su psicología. De acuerdo con él, una razón por la cual ellos sostuvieron esto es que concebían la responsabilidad en términos de "lo que depende de nosotros" y de la posibilidad de acciones alternativas, las cuales son incompatibles con la presencia de causas suficientes en nuestras acciones. En palabras del autor: "el solo hecho de admitir algo que depende de nosotros y, por tanto, el hecho de admitir las censuras y castigos para nuestras acciones erróneas implica que existe un cierto grado de indeterminación que deja librado a nuestra elección y propia determinación el camino a seguir" (Boeri 1997b, p. 164, n. 11). Asimismo:

Lo que el estoicismo antiguo llamaba "naturaleza universal" o "destino" tiene una doble dirección. En la filosofía natural significa la ley según la cual todo es y sucede en el universo de una manera determinada dentro de las secuencia causal. En la filosofía moral, en cambio, es la ley según la cual ciertos actos humanos deben ser y suceder. Si esto es así, debe existir un margen de indeterminación que dé lugar a la decisión individual. Pese al rígido determinismo causal, entonces, hay lugar para la distinción ser-deber ser, es decir, que la moralidad en términos de una conducta según la cual el sujeto $X$ tiene el poder de llevar a cabo la acción $A$ y de no llevarla a cabo es posible. (Boeri 2000, p. 23)

Me parece que estas ideas pueden exponerse bajo la forma de dos argumentos que presento a continuación.

\footnotetext{
${ }^{9}$ Expongo mi propia posición en Salles 2005, donde también discuto la relación entre el compatibilismo estoico y el de nuestros días, en particular, el de Harry Frankfurt.
} 


\section{Primer argumento}

(la) Sólo somos responsables de lo que depende de nosotros; por ejemplo, si no dependió de mí hacer $X$, no se me puede elogiar o censurar por el hecho de que $X$ haya sucedido.

Sin embargo,

(2a) sólo dependen de nosotros aquellas acciones que podemos o bien realizar o bien no realizar, esto es, la noción de algo que "depende de nosotros" presupone la noción de acciones alternativas.

Ahora bien,

(3a) el determinismo excluye que haya acciones alternativas: si mis acciones tienen una causa suficiente, no existe un sentido en que puedo o bien hacer o bien no hacer lo que de hecho hago.

Por lo tanto,

(Ca) la responsabilidad es incompatible con el determinismo aplicado a nuestras acciones y su psicología.

Segundo argumento

(1b) La censura y el elogio tienen un carga normativa que, en el caso de la censura, implica una distinción entre el ser y el deber ser, la cual, a su vez, presupone la posibilidad de acciones alternativas.

Sin embargo,

(2b) el determinismo excluye que se dé la posibilidad de acciones alternativas (por la razón mencionada en el argumento anterior, premisa [3a]).

Por lo tanto,

(Cb) la censura y el elogio son incompatibles con el determinismo aplicado a nuestras acciones y su psicología.

Aunque Boeri no lo diga de modo explícito, la primera premisa de este segundo argumento podría sustentarse en la idea de que en toda censura está implícito un juicio del tipo "no debiste hacer lo que hiciste", el cual no tendría sentido si la persona no pudo actuar 
de otro modo (el deber implica el poder o "ought implies can"; regresaré a este asunto específico en la sección 3). La segunda premisa del argumento es la misma que la segunda premisa del argumento anterior y es, por lo tanto, una supuesto común a ambos argumentos.

Los dos son válidos. Pero merece reflexión la pregunta de si son sólidos, esto es, si sus premisas expresan tesis verdaderas o por lo menos plausibles y, sobre todo, si los estoicos las aceptaron. Quisiera centrarme en el caso de las premisas $(2 \mathrm{a})$ y $(2 \mathrm{~b})[=(3 \mathrm{a})]$.

\section{La premisa (2a)}

La pregunta que se plantea en relación con la premisa (2a) es si el concepto de algo que depende de nosotros realmente presupone el de acciones alternativas. La respuesta obviamente puede variar en función de cuál sea el concepto de algo que depende de nosotros del que estemos hablando. Por lo tanto, para precisar la pregunta,

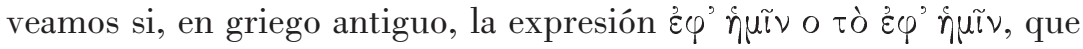
es la que se traduce, en el contexto que nos ocupa, como "lo que depende de nosotros", estuvo comúnmente asociada al concepto de acciones alternativas. Así entendida la pregunta, la respuesta parece ser negativa. Según el léxico de Liddell, Scott y Jones, ${ }^{10}$ la preposición દ̇đí con dativo transmite en primer lugar un sentido locativo que, aplicado a "nosotros" (ं் $\mu \tilde{\imath} \varsigma)$, significaría "en nosotros". Este hecho ayuda a explicar que Cicerón, al discutir el compatibilismo de Crisipo en De Fato 39-44, opte por la expresión latina "in nostra

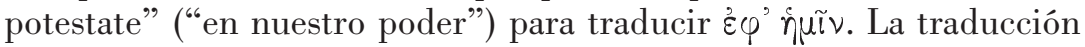
latina de Cicerón también apunta a otro de los sentidos relevantes que puede tener દ̇ंí con dativo, a saber, el causativo. ${ }^{11}$ En efecto, esta preposición puede usarse con dativo para referirse a la causa de algo o a una condición para que algo se dé. En este caso, decir de algo que es $\dot{\varepsilon} \varphi$ ' $\dot{\eta} \mu \tilde{\imath} \nu$, o que "depende de nosotros" significaría que la causa de ese algo somos nosotros y no otra cosa.

Es evidente que, en este segundo sentido, el que algo dependa de nosotros es compatible con la posibilidad de acciones alternativas, pues puede darse el caso de que una acción $X$ dependa de mí en este sentido y de que, a la vez, yo tenga la opción de no realizarla (si bien fui la causa del asalto al Expreso de Oriente, tuve la opción de no asaltarlo y de causar otra cosa en su lugar). Pero el que sean compatibles no significa necesariamente que una cosa implique la

${ }^{10}$ Liddell y Scott 1968, s.v. દ̇ंí B I. Cfr. Smyth 1920, p. 379.

${ }^{11}$ Liddell y Scott 1968, s.v. érí B III. 
otra. De hecho, no se implican recíprocamente. Para que una cosa cause otra, no es necesario que tenga la opción de no causarla. En realidad, sería necesario que no tuviera esa opción si se sostiene, junto con los deterministas causales, que toda relación causal que de hecho se da es necesaria (esto es, que no puede no darse). Por lo tanto, no me parece que, si atendemos a consideraciones léxicas, el concepto de "lo que depende de nosotros" necesariamente implique el de acciones alternativas.

Algunos autores antiguos parecen haber usado el concepto de algo que depende de nosotros en un sentido que sí conlleva el de acciones alternativas. Aristóteles, por ejemplo, en EN 3.5 1113b7-8 afirma: "En efecto, siempre que depende de nosotros ( $\dot{\varepsilon} \varphi$ " $\dot{\eta} \tilde{i} \tilde{\nu})$ el hacer, también depende el no hacer, y siempre que depende de nosotros el no, depende el sí." Aunque no se ofrece aquí una definición formal del concepto de lo que depende de nosotros, la observación sugiere claramente que Aristóteles aplica ese concepto a acciones que, en un momento dado, podemos o bien realizar o bien evitar. Sin embargo, la pregunta es si los estoicos usaron el concepto en ese sentido. Una

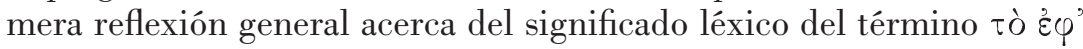

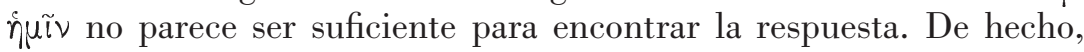
me inclino a pensar que ni siquiera hay pruebas de que algún estoico temprano haya usado el concepto de lo que depende de nosotros en un sentido que implica claramente la posibilidad de acciones alternativas. $^{12}$ En todo caso, contrariamente a lo que sugiere Boeri, no hay tales pruebas en el texto de Cicerón, De Fato 39-44.

\section{La premisa (2b)}

La premisa $(2 \mathrm{~b})$ es común a ambos argumentos, pues es también la tercera del primero. Sin embargo, ¿es realmente la posibilidad de acciones alternativas incompatible con el determinismo, como lo afirma esta premisa? Quisiera empezar la discusión trazando una distinción que utilizaré en este apartado, pero que no figura explícitamente en los trabajos de Boeri, a saber, entre una posibilidad "general" de acciones alternativas y una "específica".

Un agente $A$ tiene en un momento $t$ la posibilidad específica de realizar acciones alternativas $X$ y $Y$ si y sólo si (i) en $t$ puede realizar $X$ y (ii) en $t$ puede realizar $Y$, en vez de $X$. En cambio, $A$ tiene en $t$ la mera posibilidad general de realizar las acciones alternativas $X$ y $Y$ si, en $t, X$ y $Y$ caen en el rango de acciones que $A$ puede

\footnotetext{
${ }^{12} \mathrm{Me}$ parece que el único caso claro se da en el estoico tardío Epicteto. Al respecto, véase Salles 2005, p. 110.
} 
realizar en general, aun cuando $A$ no pueda realizar en $t$ alguna de las dos o incluso ninguna de ellas. La diferencia entre la posibilidad general y la específica puede ilustrarse mediante un ejemplo. Si fui la causa del asalto al Expreso de Oriente y por ello estoy en la cárcel cumpliendo una condena, no tengo la posibilidad de viajar en este momento. Simplemente, he de quedarme donde estoy. Por lo tanto, no tengo en este momento la posibilidad específica de realizar las acciones alternativas "quedarme o viajar". Sin embargo, aun así puedo tener en este momento la posibilidad general de realizarlas. En efecto, supongamos que mi condena es de sólo un año, y asumamos que no moriré en la cárcel. Esto significa que dentro de un año podré salir y viajar a mi antojo. En ese sentido, viajar es algo que, en este momento, cae dentro del rango de acciones que puedo realizar en un momento dado de mi vida futura (a diferencia, por ejemplo, de memorizar el Thesaurus Linguae Graeca o de retener la respiración durante media hora). Por consiguiente, tengo en este momento la posibilidad general de realizar las acciones alternativas "quedarme donde estoy o viajar", pero en este momento carezco de la posibilidad específica de realizar la segunda. Además de aclarar el significado de estos dos tipos de posibilidad, este ejemplo muestra que la general no implica la específica, aunque ésta sí implica aquélla, pues si puedo realizar una acción $X$ en $t$ y también realizar en $t$ una acción $Y$ alternativa a $X$, entonces, a fortiori, tanto $X$ como $Y$ caen en $t$ dentro del rango general de acciones que puedo realizar.

Rara vez queda claro si un autor antiguo que habla de la posibilidad de acciones alternativas se refiere a la posibilidad general o a la específica. Esto sucede con Aristóteles. Pensemos en un pasaje clásico extraído del capítulo 10 del libro 2 de la Ética Eudemia:

Ciertamente, de las cosas que es posible tanto que sean como que no sean, por un lado están aquellas que son tales que permiten la deliberación acerca de ellas [...] y éstas <sc. las cosas sobre las cuales es permisible deliberar $>$ son precisamente aquellas que depende de nosotros hacer o no hacer. (1226a 20-28)

Aristóteles no indica en este pasaje si se está refiriendo a la posibilidad de que algo "sea y no sea" en un momento específico (por ejemplo, a la posibilidad de que esta mesa, que ahora es blanca, hubiese sido roja en este mismo momento), o a la posibilidad de que algo "sea y no sea" en general (por ejemplo, a la posibilidad de que esta mesa blanca sea roja en un momento futuro). Pienso que existen otros pasajes sobre el tema, en los cuales es relativamente 
claro que Aristóteles se refiere a la posibilidad específica y no a la general. ${ }^{13}$ Pero se ha sostenido en tiempos recientes que, hasta el surgimiento del platonismo medio, el uso filosófico de la noción de posibilidades alternativas es esencialmente ambiguo en este sentido. ${ }^{14}$

Si regresamos a la pregunta de si la posibilidad de acciones alternativas es compatible con el determinismo, la respuesta debe ser afirmativa si se trata de la posibilidad general. En efecto, supongamos que, según lo exige el determinismo, hay una causa suficiente de que yo realice una acción $X$ en un momento $t_{1}$ y también una causa suficiente de que yo realice una acción $Y$ en un momento posterior $t_{2}$. El que yo haga $X$ en $t_{1}$ es el resultado necesario de la primera causa y el que yo haga $Y$ en $t_{2}$ el resultado necesario de la segunda causa. Ahora vamos a suponer que en $t_{1}$ ya está destinado que en $t_{2}$ realizaré la acción $Y$ (como sostendrían los estoicos que ocurriría, debido a su fatalismo). Esto implica que en $t_{1}$ la segunda acción ya está dentro del rango general de acciones que puedo realizar en el futuro. Y esto es así aun cuando, a todas luces (cosa que pondré en duda en la sección 4), yo no pueda realizar esa acción $Y$ en ese mismo momento $t_{1}$, pues el hecho de yo realice $X$ en $t_{1}$ parecería excluir que yo realice $Y$ en $t_{1}$ si, ex hypothesi, $X$ y $Y$ son acciones realmente alternativas. Por lo tanto, a pesar de un determinismo causal estricto como el de los estoicos, las dos acciones alternativas $X$ y $Y$ son tales que es generalmente posible que yo las realice.

Cabe observar que la posibilidad general de estados alternativos del carácter o de la personalidad es suficiente para la posibilidad del progreso moral de una persona. Para volverme una persona moralmente mejor basta que yo no esté destinado a quedarme como soy, lo cual es perfectamente compatible con que, en este momento, sea necesario que yo sea como soy y necesario también que yo sea mejor en un momento futuro. Para el progreso moral - pieza clave de la ética estoica - no se necesita la posibilidad de que, en este momento, yo fuera una persona distinta, sino sólo la posibilidad general de ser una persona distinta. Esto significa que los estoicos pueden dar cabida a la posibilidad del progreso moral por el simple hecho de que su determinismo da cabida, como ya vimos, a las posibilidades generales.

Este tema se relaciona estrechamente con la premisa (1b), la primera del segundo argumento. Como vimos al exponer ese argumento,

${ }^{13}$ Cfr. Salles 2005, pp. 78-81. Un texto clave al respecto es el de la "batalla naval" en De Int. 9, discutido en detalle por Boeri en 1997a.

${ }^{14}$ Cfr. Bobzien 1998, p. 359. 
una razón posible para afirmar que la censura implica la posibilidad de acciones alternativas es que en toda censura parecería estar implícito un juicio normativo como "Hiciste algo que no debes", el cual a primera vista supone que la persona puede no hacer lo que de hecho hizo. La idea que rige a este supuesto es sencilla: si debí hacer algo distinto de lo que de hecho hice, tuve que poder hacer algo distinto. No pretendo discutir aquí este supuesto, el cual nos lleva al problema de si tiene sentido o no decirle a alguien que debe hacer algo que le es imposible hacer, conocido en la literatura filosófica anglosajona como el problema de si "ought implies can". ${ }^{15}$ Por mor del argumento, supongamos que tal cosa no tiene sentido (y, por consiguiente, que "ought" sí implica "can"). Mi única observación es que una persona puede, en el futuro, no hacer lo que hizo en el presente, aun cuando hizo lo que hizo en el presente por necesidad causal. Por las razones que he venido presentando, esto es especialmente claro si con "puede" nos referimos a una posibilidad general de acciones alternativas.

Lo anterior, sin embargo, no agota el problema que nos ocupa, a saber, el de si la posibilidad de acciones alternativas es realmente incompatible con el determinismo. En efecto, podría argumentarse que si bien la posibilidad general es compatible con él, la específica no lo es. Pero es la específica, no la general, la que se requiere para la responsabilidad. Para merecer la censura por no haber ayudado a la anciana a cruzar la calle, es indispensable que yo, en ese momento, hubiera podido ayudarla. No basta que en el futuro yo pueda ayudarla. Sin embargo, es falso que yo haya podido ayudarla en ese momento si lo que de hecho hice (a saber, no ayudarla) fue causalmente necesario como pide el determinismo. Esta objeción es atendible y tenemos que considerar si la posibilidad específica de acciones alternativas es compatible con el determinismo causal.

\section{4. ¿Es la posibilidad específica de acciones alternativas compatible con el determinismo causal?}

El ejemplo anterior parece indicar que la respuesta a esta pregunta debe ser negativa. Pero creo que la apariencia es engañosa. En efecto, el concepto de posibilidad específica de acciones alternativas es ambiguo y en uno de sus sentidos esa posibilidad es perfectamente compatible con la necesidad causal. En efecto, una forma de entenderla es el siguiente:

\footnotetext{
${ }^{15}$ Me refiero a la literatura sobre este tema en Salles 2005, pp. 100 y 100, n. 27.
} 
$\left(\mathrm{P}_{1}\right)$ Un agente $A$ tiene en $t$ la posibilidad específica de realizar tanto la acción $X$ como la acción $Y$ (en vez de $X$ ) si $A$ tiene en $t$ la fuerza física necesaria tanto para hacer $X$ como para hacer $Y$ y si no hay en $t$ ningún obstáculo externo que le impida a $A$ ejercer esa fuerza.

Para ilustrar esta idea, pensemos en la acción de permanecer inmóvil, la cual, si bien no involucra ningún movimiento corporal, los estoicos sí clasificarían como una acción si involucra un acto de asentimiento. ${ }^{16}$ Ahora imaginemos que tengo la fuerza física para caminar (por ejemplo, no tengo los músculos atrofiados) y que nada externo me impide hacerlo (por ejemplo, no hay un muro frente a mí). En ese caso, y si nos atenemos al principio $\left(\mathrm{P}_{1}\right)$, tengo en ese momento la posibilidad específica tanto de permanecer inmóvil, cosa que de hecho hago, como de caminar en vez de permanecer inmóvil. Esto es, si por "posibilidad" entendemos lo que afirma $\left(\mathrm{P}_{1}\right)$, entonces existen en ese momento dos acciones alternativas tales que tengo la posibilidad específica de realizar cualquiera de las dos.

Me gustaría argumentar ahora que la posibilidad específica de acciones alternativas así entendida es compatible con el determinismo causal. El argumento es sencillo. El hecho de que yo tenga la fuerza física para caminar, y de que ningún obstáculo me lo impida, es él mismo compatible con que hubiera una causa suficiente interna de que yo permanezca inmóvil. Por ejemplo, un determinista podría argumentar que mi inmovilidad se deriva necesariamente del proceso racional mediante el cual llegué a la conclusión de que debía de permanecer inmóvil. Dado este proceso y dada mi racionalidad, los cuales causan mi inmovilidad, es causalmente necesario, diría el determinista, que yo permanezca inmóvil. No importa para el argumento si el determinista está en lo correcto o no. Lo que importa es el hecho de que yo tenga la fuerza física para caminar y de que ningún obstáculo me lo impida, y el hecho de que esto es compatible con que mi acción de permanecer inmóvil tenga una causa suficiente interna si la hay.

El argumento anterior es pertinente para la interpretación de los estoicos, por $\left(\mathrm{P}_{1}\right)$ expresa el modo en que el propio Crisipo parece

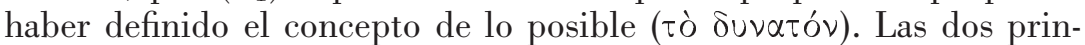
cipales fuentes son Boecio, in Ar. int. 2.234, 27-235, 4, y Diógenes Laercio 7.75. A continuación me permito citar la segunda:

${ }^{16}$ Cfr. Bobzien 1998, pp. 239-241, y Salles 2005, pp. 34-39.

Crítica, vol. 39, no. 115 (abril 2007) 


\begin{abstract}
Además, algunas cosas son posibles y otras imposibles, y algunas son necesarias y otras no necesarias. Posible es aquello que es susceptible de ser verdadero y que no está impedido por factores externos de ser verdadero, por ejemplo, Diocles está vivo. Imposible es aquello que no es susceptible de ser verdadero <o que es susceptible de ser verdadero pero está impedido por factores externos de ser verdadero $>$, por ejemplo, la tierra vuela. Necesario es aquello que, siendo es verdadero, no es susceptible de ser falso, o es capaz de ser falso pero está impedido por factores externos de ser falso, por ejemplo, la virtud es benéfica. No necesario es aquello que tanto es verdadero como susceptible de ser falso y no está impedido por factores externos de ser falso, por ejemplo, Dión camina.
\end{abstract}

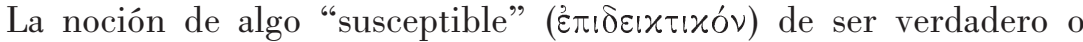
falso le fue heredada a Crisipo por Filón el Dialéctico (fines del siglo IV a.C.). No se sabe con certeza qué tipo de capacidad tienen aquí en mente Filón y Crisipo. Algunos estudiosos han afirmado que, en el caso de una acción, puede referirse simplemente a la aptitud o fuerza física del agente para realizarla. Por ejemplo, la proposición yo hago $X$ puede ser verdadera si tengo la fuerza física para hacer $X$. Asimismo, puede ser falsa si tengo la fuerza física para abstenerme de realizar la acción. En cambio, la segunda condición - estar impedido por factores externos de ser verdadero o falso- se refiere a la presencia o ausencia de factores externos a nosotros que nos impiden actuar de cierto modo o que nos obligan físicamente a actuar de modo distinto a cómo queremos. A diferencia de la primera condición, la segunda parece ser una innovación de Crisipo.

Puede observarse que, dentro de este sistema modal, la no necesidad de una proposición (y, por lo tanto, la posibilidad de su negación) es compatible con que haya causas suficientes de la acción correspondiente. Regresemos al ejemplo de la acción de permanecer inmóvil. La proposición permanezco inmóvil ahora sería no necesaria en este sistema, porque tengo la fuerza física para caminar y nada externo me lo impide. Por la misma razón, la proposición camino ahora sería posible (ahora). Pero tanto la no necesidad de permanezco inmóvil ahora como la posibilidad de camino ahora es compatible con que mi acción de permanecer inmóvil tenga una causa suficiente en mis deseos y en mi carácter. En efecto, mis deseos y mi carácter no interfieren ni con que yo tenga o no la fuerza física para caminar ni con que haya o no obstáculos externos para hacerlo. Por consiguiente, una acción necesaria dada su causa puede, no obstante, ser no necesaria desde el punto de vista del sistema modal de Crisipo. 
No hay contradicción alguna siempre y cuando supongamos que se trata de diferentes tipos o sentidos de necesidad que Crisipo no tuvo la intención de hacer equivalentes. En cuanto al motivo por el cual mi acción necesaria es responsable en este caso es que su causa radica en mi carácter. Por lo tanto, se trata de una acción que yo apruebo plenamente y, dada mi aprobación, el hecho de que la acción sea necesaria no debilita ni afecta en lo más mínimo mi responsabilidad por ella. En otras publicaciones he intentado mostrar que esta intuición - presente en compatibilistas modernos recientes - ya figura en algunos testimonios sobre los estoicos. ${ }^{17}$ Lo que importa subrayar por ahora es que, en un sentido de "posibilidad" que los propios estoicos parecen haber aceptado, la posibilidad específica de acciones alternativas es compatible con el determinismo causal. Pero si una cosa es compatible con la otra, entonces, para dar cabida a la responsabilidad, ¿por qué habría un estoico de abrir un margen de indeterminación, como sostiene Boeri?

\section{Recapitulación y conclusión}

A pesar de todo lo anterior, un incompatibilista podría no quedar satisfecho. Aun cuando, en un sentido, la posibilidad específica de acciones alternativas sea compatible con el determinismo, este sentido es demasiado débil. En todo caso, no refleja el tipo de posibilidad que realmente se necesita para la responsabilidad. Esta última requiere que yo tenga la posibilidad de acciones alternativas en el sentido fuerte de que ninguna de mis acciones sea el resultado necesario de causas suficientes. En pocas palabras, la responsabilidad presupone el indeterminismo causal. En ese caso, en efecto, la responsabilidad sería, por definición, incompatible con el determinismo causal.

Si los estoicos hubiesen aceptado esta tesis incompatibilista fuerte, efectivamente habrían tenido que abrir un margen de indeterminismo dentro de su teoría de la acción y de su sistema causal en general para dar cabida a la responsabilidad, como lo sugiere Boeri. No creo que existan pruebas textuales contundentes de que los estoicos hayan hecho realmente esta concesión. En concreto, me parece difícil encontrar un texto en que, sin ninguna ambigüedad, se les atribuya la tesis de que algo sólo depende de nosotros si carece de una causa suficiente. Aunque algunos textos puedan interpretarse en ese sentido, como lo hace Boeri, esos mismos textos pueden interpretarse en un sentido determinista. Tal es el caso de los párrafos 41-43 del

\footnotetext{
${ }^{17}$ Cfr. Salles 2000 y 2005, pp. 56-68.
} 
De Fato de Cicerón. ${ }^{18}$ Dicho de otro modo, ambas interpretaciones están subdeterminadas por la evidencia textual. Pero, desde el punto de vista conceptual, no creo que haya razones suficientes para suponer que los estoicos aceptaron la ausencia de necesidad en la esfera de las acciones y de su psicología. Como he intentado mostrar en este trabajo, el simple hecho de que usen los conceptos de lo que depende de nosotros y de posibilidad de acciones alternativas no los compromete conceptualmente a aceptar esta ausencia. ${ }^{19}$

\section{BIBLIOGRAFÍA}

Boeri, M.D., 2000, "El determinismo estoico y los argumentos compatibilistas de Crisipo", Cuadernos del Sur, vol. 29, pp. 11-47.

-, 1997a, "Aristóteles, el estoicismo antiguo y lo que depende de nosotros", Méthexis, vol. 10, pp. 161-172.

_- 1997b, "El problema de la libertad y el estoicismo antiguo", Hypnos, vol. 3, pp. 159-167.

Bobzien, S., 1998, Determinism and Freedom in Stoic Philosophy, Oxford University Press, Oxford.

Liddell, H.G. y R. Scott, 1968, A Greek-English Lexicon, ed. rev. y aum. por H.S. Jones, Clarendon Press, Oxford.

Salles, R., 2005, The Stoics on Determinism and Compatibilism, Ashgate, Londres. [Versión en castellano: Los estoicos y el problema de la libertad, Instituto de Investigaciones Filosóficas-UNAM, México, 2006.]

__ 2000, "Compatibilism: Stoic and Modern", Archiv für Geschichte der Philosophie, vol. 83, pp. 1-23.

Smyth, H.W., 1920, Greek Grammar, Harvard University Press, Cambridge, Mass. (reimp. 1984).

Sorabji, R., 2003 (1980), Necesidad, causa y culpa. Perspectivas sobre la teoría de Aristóteles, trad. Ricardo Salles, Instituto de Investigaciones Filosóficas-UnAM, México. (Publicado originalmente en inglés: Necessity, Cause and Blame. Perspectives on Aristotle's Theory, Duckworth, Londres, 1980.)

Recibido el 31 de marzo de 2006; aceptado el 8 de noviembre de 2006.

${ }^{18}$ Para una lectura determinista, $c f r$. Salles 2005, pp. 42-49. Para una lectura indeterminista, véase, además de Boeri 2000, Bobzien 1998, pp. 250-313.

${ }^{19}$ Estoy muy agradecido con los tres dictaminadores anónimos a quienes fue enviada una primera versión del trabajo por sus útiles sugerencias. También quiero agradecer al propio Marcelo Boeri, quien, además de hacer varias precisiones a mi reconstrucción de su interpretación, se tomó la molestia de responder por escrito a mis comentarios críticos. La redacción de este trabajo se realizó en el marco del proyecto PAPIIT IN 407705 de la UNAM. 